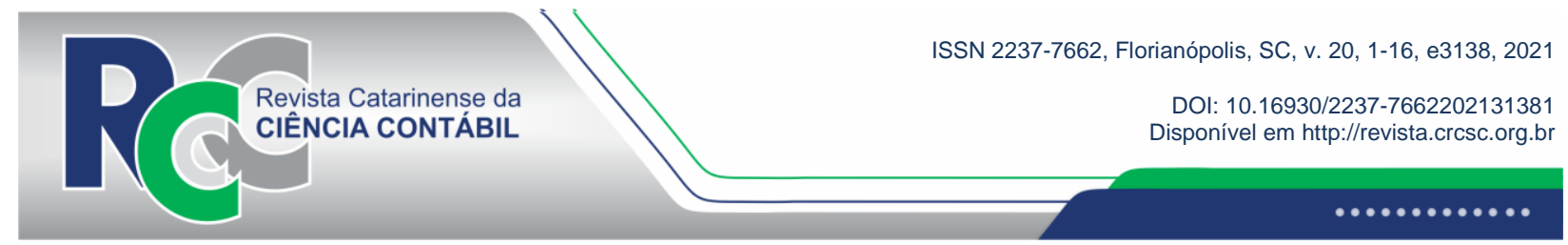

\title{
ESCRITÓRIOS DE CONTABILIDADE E SUA RELAÇÃO COM OS CLIENTES FRENTE À CRISE DA COVID-19
}

\section{ACCOUNTING FIRMS AND THEIR RELATIONSHIP WITH CLIENTS IN THE FACE OF THE COVID-19 CRISIS}

\author{
FABIANA FRIGO SOUZA \\ Universidade Federal do Paraná. Endereço: Av. Pref. \\ Lothário Meissner, 632| Jardim. Botânico | 80210-070| \\ Curitiba/PR| Brasil. \\ (1) https://orcid.org/0000-0003-0475-8997 \\ fabiiana_fs@hotmail.com
}

\author{
RICARDO BIERNASKI KACHENSKI \\ Universidade Federal do Paraná. Endereço: Av. Pref. \\ Lothário Meissner, 632| Jardim. Botânico | 80210-070 | \\ Curitiba/PR| Brasil. \\ (1) https://orcid.org/0000-0001-9577-2836 \\ ricardobiernaski@yahoo.com
}

\section{FLAVIANO COSTA}

Universidade Federal do Paraná. Endereço: Av. Pref. Lothário Meissner, 632| Jardim. Botânico | 80210-070| Curitiba/PR| Brasil.

(1) https://orcid.org/0000-0002-4694-618X

flaviano@ufpr.br

\section{RESUMO}

O suporte gerencial pode ser entendido como a área que auxilia na tomada de decisões relacionadas a gestão (desempenho organizacional, planejamento financeiro e controle). Sugere-se que as mudanças ocasionadas pela COVID-19 têm impactado a forma como a contabilidade, de modo especial no que tange ao aspecto gerencial, vem sendo utilizada pelas empresas e pelos escritórios de contabilidade. Neste contexto, a pesquisa teve como objetivo identificar como a crise causada pela COVID-19 afetou o suporte gerencial ofertado pelo contador. O estudo caracteriza-se como uma pesquisa descritiva, com enfoque qualitativo, cuja operacionalização foi conduzida por meio de um roteiro previamente definido, com seis escritórios de contabilidade localizados nos estados de Santa Catarina, Paraná e São Paulo (Brasil). Quanto à análise dos dados, utilizou-se a técnica de análise de conteúdo. Os resultados revelaram que a crise da COVID-19 apresentou, em seus primeiros meses, potencial para geração de mudanças na relação entre escritórios de contabilidade e seus clientes, impactando o suporte gerencial ofertado pelos contadores. Ademais, observou-se que as consequências decorrentes da crise ocasionaram um processo de ampliação do entendimento sobre o papel da contabilidade, em relação ao processo de tomada de decisão. Nesse

Editado em português e inglês. Versão original em português.

Recebido em 8/1/2021. Revisado em 7/6/2021. Aceito em 24/6/2021 pelos Prof. Dr. Sérgio Murilo Petri (Editor-Chefe) e Prof. Dr. Sandro Vieira Soares (Editor Adjunto). Publicado em 23/8/2021.

Copyright @ 2021 RCCC. Todos os direitos reservados. É permitida a citação de parte de artigos sem autorização prévia, desde que identificada a fonte. 
sentido, o estudo contribui não só para o entendimento sobre as formas como a pandemia da COVID-19, em seu estágio inicial, influenciou e permanece influenciando as relações humanas e, principalmente, as profissionais no âmbito da contabilidade, como também mostrar as oportunidades decorrentes do momento vivenciado, para que os escritórios de contabilidade se aproximem de seus clientes.

Palavras-chave: COVID-19. Contabilidade. Suporte gerencial. Empresas prestadoras de serviços contábeis.

\begin{abstract}
Management support can be understood as the area that assists in decision-making related to management (organizational performance, financial planning, and control). It is suggested that the changes brought about by COVID-19 have impacted the way accounting - especially in terms of management - has been used by companies and accounting firms. In this context, the research aimed to identify how the crisis caused by COVID-19 has affected the management support offered by accountants. The study is characterized as a descriptive research, with a qualitative focus, whose operationalization was conducted by means of a previously defined script, with six accounting firms located in the states of Santa Catarina, Parana and Sao Paulo (Brazil). As for the data analysis, the content analysis technique was used. The results revealed that the COVID19 crisis presented, in its first months, the potential to generate changes in the relationship between accounting firms and their clients, impacting the management support offered by accountants. Furthermore, it was observed that the consequences of the crisis led to a process of broadening the understanding of the role of accounting in the decision-making process. In this sense, the study contributes not only to the understanding of the ways in which the pandemic of COVID-19, in its initial stage, has influenced and continues to influence human relationships and, especially, professional relationships in the field of accounting, but also to show the opportunities arising from the moment experienced, so that accounting firms get closer to their clients.
\end{abstract}

Keywords: COVID-19. Accounting. Management support. Companies providing accounting services.

\title{
1 INTRODUÇÃO
}

O ano de 2020 foi marcado pelo início de uma pandemia decorrente do novo coronavírus, cuja origem ainda incerta é atribuída ao Huanan Seafood Wholesale Market, na cidade de Wuhan, na China, que apresentou os primeiros casos da doença ainda em dezembro de 2019 (Crawford et al., 2020). Como resposta à rápida transmissão do vírus e à gravidade dos atingidos, a Organização Mundial da Saúde (OMS) declarou, em 11 de março de 2020, quando os casos de infectados chegaram a mais de 118 mil no mundo, que se tratava de uma pandemia (OMS, 2020).

Assim, desde os primeiros meses do ano, como forma de diminuir os efeitos da doença, países têm anunciado o fechamento de estabelecimentos ou a alteração do funcionamento das suas atividades, como academias, museus, cinemas, escolas, entre outros (Sahu, 2020), gerando impacto direto na vida de seus cidadãos e na economia das empresas e do país como um todo (Polizzi, Lynn, \& Perry, 2020; Sintema, 2020; Sahu, 2020). Apesar disso, tem-se, atualmente, mais de 170,4 milhões de pessoas infectadas e mais de 3,5 milhões de mortes no mundo decorrentes dos efeitos da COVID-19 (OMS, 2021).

No Brasil, onde o primeiro caso foi registrado em 4 de março de 2020, segundo dados disponibilizados pelo Ministério da Saúde (Brasil, 2020), pouco se sabe sobre os efeitos da doença, seja em termos econômicos, políticos ou sociais. A esse respeito, sabe-se que uma das áreas impactadas pelos efeitos da pandemia é a contabilidade, cujas dinâmicas e atividades foram afetadas, assim como ocorreu com a vida e os negócios de todos ao redor no mundo (Sintema, 
2020). Cabe destacar, no entanto, que a contabilidade pode servir como vetor para o enfrentamento e gerenciamento da crise econômica gerada pela COVID-19, decorrente principalmente do fechamento das empresas e da restrição à mobilidade humana (Kraemer et al., 2020), o que potencializou a instabilidade econômica mundial e brasileira (Ferreira Junior \& Santa Rita, 2020).

Dessa forma, a contabilidade, sobretudo em relação ao aspecto gerencial e ao suporte à tomada de decisão, pode auxiliar as empresas a alcançar os objetivos organizacionais (Chenhall \& Langfield-Smith, 1998) que, nesse momento, podem se traduzir em manter as empresas ativas e superar os efeitos da crise causada pela pandemia. Apesar disso, há o entendimento de que as empresas não têm conseguido absorver a utilidade da contabilidade gerencial (Green \& Amenkhienan, 1992; Lukka \& Granlund, 2002; Abdel-Kader \& Luther, 2006), seja por falta de conhecimento e estrutura, seja pelo suporte oferecido pelos contadores, principalmente quando são atendidos por escritórios de contabilidade (Santos, Bennert, Figueiredo, \& Beuren, 2018).

Neste contexto, entende-se que a pandemia da COVID-19 afetou a vida e o comportamento das pessoas em todo o mundo, gerando sentimentos de incerteza e ansiedade em relação ao futuro (Sahu, 2020; Sintema, 2020), tanto em aspectos pessoais quanto organizacionais. Assim, sugerese que essas mudanças também possam influenciar a forma como a contabilidade, principalmente no aspecto gerencial - que pode ser entendido como a área cujo foco está na parceria na tomada de decisões relacionadas à gestão, com o auxílio à avaliação do desempenho organizacional, ao planejamento financeiro e à aspectos de controle (IMA, 2008) -, vem sendo utilizada pelas empresas e pelos escritórios de contabilidade, que podem passar a ser vistos, dado o momento de insegurança, como uma saída para o enfrentamento da crise, com a contabilidade atuando frente ao sofrimento e à desigualdade (Sargiacomo, Ianni \& Everett, 2014), nos aspectos social e econômico. Portanto, este estudo busca responder a seguinte questão de pesquisa: como a crise causada pela COVID-19 afetou o suporte gerencial ofertado pelos escritórios de contabilidade? Para responder ao problema proposto, tem-se como objetivo identificar como a crise afetou o suporte gerencial ofertado pelo contador.

Chahrour et al. (2020) evidenciam que a COVID-19 tem sido o foco principal de pesquisadores ao redor do mundo, com um montante de publicações que ultrapassava $1.500 \mathrm{em}$ março de 2020. Esse movimento tem acontecido em função das mudanças sem precedentes, enfrentadas por todos os setores da sociedade, a partir desta pandemia (Polizzi et al., 2020; Massan, Shaikh, \& Dahri, 2020), bem como da busca pela cura e redução dos efeitos da doença (Chahrour et al., 2020).

Nesse sentido, estudos têm analisado aspectos psicológicos (e. g., Wang et al., 2020), educacionais (e.g., Cao et al., 2020) e econômicos (e.g., Ferreira Junior \& Santa Rita, 2020) em âmbito nacional e internacional. Porém, dado o caráter recente da doença e de seus impactos, pouco se sabe, ainda, sobre seus efeitos no mundo e no Brasil. Assim, Massan et al. (2020) defendem a produção de pesquisas relacionadas à temática.

\section{SUPORTE GERENCIAL DOS ESCRITÓRIOS DE CONTABILIDADE}

A contabilidade gerencial pode ser vista como a área da contabilidade que tem como um de seus objetivos o fornecimento de controles e relatórios financeiros com vistas à tomada de decisão (IFAC, 1998; IMA, 2008). Tais controles e relatórios podem ser fornecidos a partir de métodos, ferramentas ou práticas mais sofisticadas, como Balanced Scorecard, ou, de forma mais simplificada, como o uso de orçamentos tradicionais e medidas de desempenho baseadas em lucro (Abdel-Kader \& Luther, 2006), representando um suporte gerencial para as tomadas de decisões no âmbito organizacional.

Em empresas com recursos restritos, como é o caso das microempresas, empresas de pequeno porte e até organizações de médio porte, a adoção de tais práticas enfrenta barreiras relacionadas, principalmente, à falta de conhecimento e de estrutura (Ahmad \& Zabri, 2016). Dessa forma, estudos têm sido realizados na busca pelo entendimento sobre como essa área do 
conhecimento tem sido utilizada pelas empresas menos estruturadas (e. g. Ahmad \& Zabri, 2016; Armitage, Webb \& Glynn, 2016; Prihastiwi \& Sholihin, 2018; Santos et al., 2018), que são as principais impactadas pelos efeitos de uma crise.

Ahmad e Zabri (2016) realizaram um estudo com 160 pequenas e médias empresas da Malásia, cujo objetivo era identificar a utilização de ferramentas gerenciais. Os resultados indicaram um uso mais elevado de práticas de contabilidade gerencial pelas médias empresas, em comparação às pequenas. Além disso, as técnicas gerenciais mais básicas, como aspectos relacionados a orçamento, desempenho e custeio, foram as mais adotadas entre as empresas analisadas. Como justificativa para esse resultado, os autores sugerem aspectos como os custos envolvidos, aspectos práticos e incerteza relacionada a adoção de ferramentas gerenciais.

O estudo de Armitage et al. (2016) teve como objetivo identificar o uso das técnicas de contabilidade gerencial por pequenas e médias empresas da Austrália e do Canadá. A partir de 22 entrevistas (11 com empresas do Canadá e 11 com empresas da Austrália), os autores identificaram que empresas industriais apresentaram uso de uma maior quantidade de ferramentas gerenciais e, em contrapartida, que as empresas menores utilizam tais práticas de forma mínima, mencionando, principalmente, o controle e gestão do fluxo de caixa. Em relação às práticas não utilizadas, os autores mencionam que os entrevistados as conheciam, na maioria dos casos, mas justificavam o não uso em função da análise do custo-benefício, já que recurso é um elemento normalmente escasso entre organizações menores.

Prihastiwi e Sholihin (2018) realizaram estudo com pequenas e médias empresas na Indonésia com o objetivo de identificar o nível de adoção de ferramentas gerenciais. A partir das 124 respostas obtidas, identificaram que as principais práticas utilizadas pelas empresas eram as consideradas tradicionais, em detrimento das mais recentes. Em relação aos fatores que justificam essa aplicação, os autores identificaram que a qualificação da equipe de contabilidade, o tamanho e a participação do proprietário ou gestor influenciavam a adoção das práticas gerenciais. Aparece aqui, portanto, além de outros fatores, a relação entre o contador e a empresa, no que tange o suporte gerencial.

Santos et al. (2018) buscaram verificar o papel dos escritórios de contabilidade no uso de práticas gerenciais por pequenas e médias empresas brasileiras. A partir da resposta de 39 empresas, os autores identificaram que a maioria dos gestores desconhece ou não utiliza instrumentos gerenciais. Em relação aos que utilizam alguma ferramenta para a gestão do negócio, estas não são fornecidas pelo escritório de contabilidade, podendo indicar ruídos na comunicação entre clientes e seus prestadores de serviços contábeis.

Assim, percebe-se que o contador e as empresas de contabilidade também fazem parte do contexto de baixo uso de ferramentas gerenciais pelas corporações, pois parte desses profissionais ou escritórios parece não fornecer suporte para que essas empresas profissionalizem sua gestão. Em tempos de crise, esse fato se torna mais crucial, dada a necessidade de um processo decisório mais rápido para o enfrentamento dos efeitos da COVID-19 e visto que, como defende Ahmad (2012), as empresas, principalmente pequenas e médias, devem utilizar as informações contábeis para lidar com futuros desafios. Nesse sentido, entende-se que, embora os estudos apresentem baixo uso de ferramentas gerenciais por empresas de pequeno porte e a baixa oferta desse serviço pelos escritórios contábeis, uma crise, como a gerada pelo novo coronavírus, pode mudar tal situação.

\section{PROCEDIMENTOS METODOLÓGICOS}

No que se refere ao enquadramento metodológico, o estudo utilizou a categorização proposta por Sampieri, Collado e Lucio (2013). Assim, caracteriza-se como uma pesquisa nãoexperimental, transversal, descritiva e com enfoque qualitativo.

Em termos operacionais, optou-se pela utilização de entrevistas. A técnica de entrevista "fornece os dados básicos para o desenvolvimento e a compreensão das relações entre os atores 
sociais e sua situação" (Gaskell, 2015, p. 65), visando a uma compreensão detalhada sobre os comportamentos dos indivíduos em circunstâncias sociais específicas. Tal técnica foi semiestruturada e com profundidade (Martins \& Theóphilo, 2016), uma vez que foi conduzida por um roteiro, porém com liberdade de acrescentar novas questões no decorrer do processo.

$\mathrm{O}$ roteiro semiestruturado utilizado foi elaborado pelos autores e contém questões derivadas das inquietações dos pesquisadores acerca do novo momento que o mundo vivencia, em decorrência da pandemia da COVID-19 (Sahu, 2020) e que afeta empresas, contadores e a prestação dos serviços contábeis.

Salienta-se que antes do início da realização das entrevistas, o roteiro semiestruturado foi validado por dois especialistas da área de contabilidade que também têm realizado pesquisas acerca da temática do novo coronavírus. Após a validação, foram realizados não só ajustes em algumas questões, como também outras foram acrescentadas ao roteiro de entrevista. Adicionalmente, sua separação por blocos também foi resultado dos apontamentos dos especialistas. Assim, o roteiro de entrevista final utilizado na pesquisa é composto por 14 questões, divididas em três blocos: Suporte Gerencial; Perfil do Entrevistado; Perfil da Empresa. Na Tabela 1, apresenta-se o detalhamento do roteiro final, com as questões de cada bloco.

\section{Tabela 1}

\section{Roteiro Final da Pesquisa}

\section{Suporte Gerencial}

1. O que você compreende por suporte gerencial? Que tipo de suporte gerencial o contador deve oferecer hoje aos seus clientes?

2. Na sua percepção, o(a) contador(a) é visto pelas empresas como suporte gerencial diante de uma pandemia como esta?

3. Você acredita que seus clientes enxergam o seu escritório como um elemento fundamental para manter a saúde da empresa deles? Você acha que a crise gerada pela COVID-19 pode mudar essa visão?

4. Quais serviços de suporte à gestão dos clientes o Sr.(a.) costumava oferecer?

5. Esses serviços foram alterados com a chegada da Pandemia da COVID-19? Se sim, quais foram as alterações? O que incentivou a realização dessas alterações dentro do escritório de contabilidade?

6. Como a crise gerada pela COVID-19 pode mudar a curto e longo prazo a relação entre cliente e contador?

7. Na sua percepção, a visão sobre o suporte gerencial que os contadores podem oferecer para as empresas foi modificada em função da COVID-19? Essas modificações tendem a acompanhar os serviços prestados a longo prazo?

8. O Sr.(a.) percebeu um aumento da procura do contador durante a pandemia da COVID-19? Caso a resposta seja sim, por que você acha que isso aconteceu? Que cenário político, econômico e social contribuiu para tal comportamento das pessoas? Algumas provocações: medidas provisórias relacionadas ao vínculo empregatício, possibilidade de suspensão dos pagamentos de impostos e possibilidade de financiamentos.

\begin{tabular}{|c|}
\hline Perfil do Entrevistado \\
\hline 1. Há quantos anos seu escritório de contabilidade está em atividade? \\
\hline 2. Qual a sua maior formação? Algumas provocações: especialização, mestrado e doutorado. \\
\hline Perfil da Empresa \\
\hline $\begin{array}{l}\text { 1. Em qual cidade está localizado o seu escritório de contabilidade? Caso haja mais de uma unidade, considerar a } \\
\text { matriz ou principal. }\end{array}$ \\
\hline 2. Quantos funcionários/colaboradores o escritório possui? \\
\hline 3. Aproximadamente, quantos clientes seu escritório possui? \\
\hline $\begin{array}{l}\text { 4. Na sua visão, qual o perfil dos seus clientes? Algumas provocações: micro e pequenas empresas, porte médio, } \\
\text { porte grande e estrutura familiar. }\end{array}$ \\
\hline
\end{tabular}

Fonte: Elaborado pelos autores (2020).

Vale ressaltar que se optou por não direcionar os respondentes com perguntas que incluíssem as características do suporte gerencial, já que o foco está em entender suas percepções, em maior profundidade, a partir dos participantes do estudo. Portanto, o entendimento sobre o suporte gerencial e a forma como ele era ofertado antes e após a pandemia foi obtido a partir da visão dos entrevistados. Adicionalmente, menciona-se que, em termos do porte dos clientes dos 
escritórios participantes da pesquisa, optou-se pela sua classificação de forma subjetiva, também a partir da percepção dos entrevistados.

A população-alvo da pesquisa constitui-se de escritórios de contabilidade, e a seleção dos participantes se deu por conveniência e acessibilidade - sócios-proprietários de escritórios de contabilidade do Paraná, Santa Catarina e São Paulo que aceitaram participar da pesquisa. Os escritórios selecionados apresentavam estruturas e tamanhos distintos, de forma a identificar, nos diferentes casos, de que forma a pandemia da COVID-19 influenciou na oferta de suporte gerencial. Fez-se, inicialmente, um primeiro contato com os possíveis participantes (donos de escritórios de contabilidade), no qual foi explicado o objetivo do estudo. Na sequência, após aceitarem participar da investigação, houve o agendamento de uma data e horário para a realização das entrevistas. Em nenhum momento os participantes foram coagidos a participar do estudo, bem como não foi oferecido nenhum tipo de recompensa material ou imaterial para o grupo de interesse da pesquisa. Antes do início da entrevista, foi feita uma nova explicação acerca do objetivo do estudo, além de uma breve apresentação do roteiro e dos pesquisadores. Neste momento também foi solicitada a autorização dos participantes para a gravação da entrevista.

As entrevistas foram realizadas de forma online, justificada pela localização geográfica dos participantes (Paraná, Santa Catarina e São Paulo) e pela própria pandemia. Embora a entrevista online apresente algumas limitações, dentre elas "as partes não-verbais ou paralinguísticas da comunicação são difíceis de transportar e de integrar" (Flick, 2009, p. 243), é uma forma de substituir uma entrevista realizada pessoalmente e tem como vantagem o fato de integrar à investigação participantes que não são acessíveis como, por exemplo, aqueles que vivem longe. Assim, dada a escolha pela operacionalização online, as entrevistas foram realizadas por meio dos aplicativos Skype e Zoom.

As reuniões aconteceram entre os dias 13 e 29 de maio de 2020, aproximadamente dois meses após a chegada da pandemia no Brasil, com duração média de 33 minutos, como pode ser observado na Tabela 2.

Tabela 2

\section{Dados das entrevistas}

\begin{tabular}{l|c|c|c}
\hline \multicolumn{1}{c|}{ Participante } & Data & Duração & Ferramenta \\
\hline Entrevistado 1 & $13 / 05 / 2020$ & $00: 46: 28$ & Zoom \\
\hline Entrevistado 2 & $14 / 05 / 2020$ & $00: 24: 55$ & Skype \\
\hline Entrevistado 3 & $20 / 05 / 2020$ & $00: 18: 50$ & Skype \\
\hline Entrevistado 4 & $27 / 05 / 2020$ & $01: 01: 10$ & Skype \\
\hline Entrevistado 5 & $28 / 05 / 2020$ & $00: 23: 33$ & Skype \\
\hline Entrevistado 6 & $29 / 05 / 2020$ & $00: 25: 41$ & Skype \\
\hline
\end{tabular}

Fonte: Dados da pesquisa (2020).

Quanto à saturação da coleta de dados, buscou-se, no processo da pesquisa, dar corpo ao objeto do estudo, não se preocupando com a quantidade de entrevistas, mas com a qualidade das informações. Minayo (2017) destaca que pesquisadores têm se pronunciado referente aos questionamentos quanto ao momento de saturação nas pesquisas qualitativas, porém não há um consenso definitivo sobre a problemática. Assim, destaca-se que, durante o período de realização das entrevistas, os pesquisadores avaliaram o saturamento das respostas obtidas e identificaram que tal fato aconteceu quando da obtenção de 6 participantes, quando, apesar das diferenças em termos de estrutura, houve uma repetição nas respostas dadas. Portanto, como se refere Miyano (2017), a saturação se deu pela visão dos pesquisadores quando perceberam ter encontrado a lógica interna do objeto de estudo, mesmo verificando a característica de expressões verbais diretas e simples nas falas dos entrevistados.

Após a finalização, as entrevistas foram transcritas para fins de análise. Feita a transcrição, foi possível a criação de categorias de análises. A categorização "[...] é um processo de tipo estruturalista e envolve duas etapas: o inventário (isolamento das unidades de análise: palavras, 
temas, frases etc.) e a classificação das unidades comuns, revelando as categorias (colocação em gavetas) [...]" (Martins \& Theóphilo, 2016, p. 99).

Feitos esses procedimentos, os dados coletados a partir das entrevistas foram tratados com a técnica de análise de conteúdo. A análise de conteúdo é uma técnica para produzir inferências de forma objetivada (Bauer, 2015). De acordo com Bardin (2009), a análise de conteúdo é "um conjunto de técnicas de análise das comunicações visando obter por procedimentos sistemáticos e objectivos de descrição do conteúdo das mensagens indicadores (quantitativos ou não) que permitam a inferência de conhecimentos relativos às condições de produção/recepção [...] destas mensagens" (p. 44). Na análise das entrevistas, os participantes foram codificados para que não fossem identificados.

\section{APRESENTAÇÃO E DISCUSSÃO DOS RESULTADOS}

Em termos da caracterização dos entrevistados e de seus escritórios, há uma variedade tanto em relação ao tempo de atividade quanto ao porte, seja em termos da quantidade de clientes ou do número de funcionários. Os dados referentes a esta caracterização estão apresentados na Tabela 3.

Tabela 3

Caracterização dos participantes e dos seus escritórios de contabilidade

\begin{tabular}{c|c|c|c|c|c}
\hline Respondente & Formação & $\begin{array}{c}\text { Atuação do } \\
\text { escritório }\end{array}$ & $\mathbf{N}^{\mathbf{o} \text { funcionários }}$ & $\begin{array}{c}\mathbf{N}^{\mathbf{0}} \\
\text { client } \\
\text { es }\end{array}$ & $\begin{array}{c}\text { Porte } \\
\text { clientes }\end{array}$ \\
\hline Entrevistado 1 (E1) & $\begin{array}{c}\text { Técnico em Contabilidade, } \\
\text { graduação em Administração e } \\
\text { pós-graduação em Pedagogia }\end{array}$ & 30 anos & 15 & 70 & $\begin{array}{c}\text { Pequeno a } \\
\text { médio porte }\end{array}$ \\
\hline Entrevistado 2 (E2) & $\begin{array}{c}\text { Pós-graduação em Perícia } \\
\text { Contábil, Trabalhista e } \\
\text { Tributária }\end{array}$ & 1 ano & 0 (2 sócios) & 12 & $\begin{array}{c}\text { Micro e } \\
\text { pequenas }\end{array}$ \\
\hline Entrevistado 3 (E3) & $\begin{array}{c}\text { Pós-graduação na área } \\
\text { tributária em andamento }\end{array}$ & 10 anos & 2 & 50 & $\begin{array}{c}\text { Micro e } \\
\text { pequenas }\end{array}$ \\
\hline Entrevistado 4 (E4) & $\begin{array}{c}\text { Mestrado em Contabilidade } \\
\text { Entrevistado 5 (E5) }\end{array}$ & 6 anos & 40 & 250 & $\begin{array}{c}\text { Pequeno a } \\
\text { médio porte }\end{array}$ \\
\hline Eraduação em Contabilidade & 60 anos & 10 & 250 & $\begin{array}{c}\text { Pequeno a } \\
\text { médio porte }\end{array}$ \\
\hline Entrevistado 6 (E6) & $\begin{array}{c}\text { Mestrado em Contabilidade em } \\
\text { andamento }\end{array}$ & 5 anos & 2 & 40 & $\begin{array}{c}\text { Micro e } \\
\text { pequenas }\end{array}$ \\
\hline
\end{tabular}

Fonte: Dados da pesquisa (2020).

Percebe-se, portanto, que os entrevistados possuem escritórios que atendem empresas de portes distintos e que estão, também, em momentos diferentes, em termos de sua constituição como empresa e em relação a sua estrutura.

Essa heterogeneidade entre os entrevistados reflete-se na forma como eles compreendem o suporte gerencial e as possibilidades de oferecimento de tal suporte por parte dos seus escritórios de contabilidade. Em termos da compreensão acerca do suporte gerencial, percebe-se um entendimento geral relacionado ao auxílio à tomada de decisões, alinhado ao que preconiza o IMA (2008) sobre o papel da contabilidade gerencial e do contador. Apesar disso, é possível observar, quanto à profundidade do termo, um distanciamento nas respostas. Esses distanciamentos podem ser visualizados pelas falas dos entrevistados E3 e E4, que asseveram que "o gerencial que eu entendo seria isso, essa contabilidade em dia, para com o resultado apurado para poder passar informação para o cliente [...]" (E3) e "[...] o contador tem um papel fundamental nisso seja ofertando serviços financeiros, ajudando na gestão do negócio, [...] ajudando na organização e determinação de processos internos, processos de controle internos, geração de informações em tempo real" (E4). 
Com relação ao que deveria ser ofertado aos clientes, percebeu-se uma distinção em relação ao direcionamento que os respondentes indicam como foco do suporte gerencial. Por um lado, existe uma visão mais relacionada e limitada às tomadas de decisões no âmbito financeiro e tributário; por outro, de um suporte que parece estar mais relacionado aos aspectos do alcance dos objetivos organizacionais, como pode ser identificado a partir das falas dos entrevistados E5, E2 e E4. O Entrevistado 5 afirmou que "[...] principalmente um suporte na área financeira, como controlar suas finanças, como utilizar ferramentas e métodos para apuração de resultados, como aplicar internamente sistemas e ferramentas de gestão que realmente gerem informação em tempo real [...]". Complementarmente, o Entrevistado 2 ponderou que "[...] e aí eu acredito que a parte gerencial entre mais a fundo, em questão de próprios índices, enfim, instrumentos gerenciais que possam realmente auxiliar e trazer um efeito para empresa, um resultado maior para a empresa". Finalmente, em adição, o Entrevistado 4 defendeu que

[...] para justamente dar esse suporte gerencial que ele precisa, seja a nível de fluxo de caixa, seja a nível de indicadores, seja a nível de projeção de resultados, planejamento tributário, e por aí vai, acho que são muitas as informações que o contador pode ajudar a fornecer e muitas vezes ajudar também a compreender os resultados (E4)

Portanto, nota-se que a visão dos entrevistados acerca do que consiste o aspecto gerencial e das possibilidades de oferta de ferramentas relacionadas está mais voltada aos estágios iniciais da contabilidade gerencial, como definido pelo IFAC (1998), onde o foco está centrado na determinação dos custos e no controle financeiro. Nesse sentido, considerando que a maior parte dos clientes dos escritórios analisados são pequenas e médias empresas, e que os entrevistados entendem o suporte gerencial como um aspecto voltado ao controle financeiro, estes achados parecem se alinhar aos de Armitage et al. (2016), que identificaram que empresas menores têm seu suporte gerencial centrado em informações financeiras.

No entanto, percebe-se que os escritórios de contabilidade parecem não estar ofertando o suporte gerencial nesse nível, e que este fato pode estar relacionado a barreiras que são impostas pelos próprios clientes, como destacam os entrevistados E1 e E2. O Entrevistado 1 aduziu que “[...] a gente não está ainda nesse nível de suporte gerencial, acredito que, a gente esteja em um suporte operacional. Pelo menos a grande maioria, em termos de escritório de contabilidade" (E1). Além disso, o E2 observou que

O que eu vejo muito de dificuldade, assim, em prestar informação gerencial, é que muitas vezes, para o próprio empresário acaba não sendo interessante, ele não vê no contador uma pessoa que possa auxiliar neste sentido [...] pouquíssimos empresários têm esse feeling de querer que o contador se meta (E2)

Da mesma forma, Ahmad e Zabri (2016) identificaram que algumas barreiras influenciam não só na oferta de suporte gerencial, mas também na adoção de suas ferramentas por parte das empresas, e estão relacionadas à falta de conhecimento e de estrutura, principalmente por parte de pequenas empresas, o que parecem ser, também, as barreiras enfrentadas pelos escritórios de contabilidade entrevistados e seus clientes.

Em relação aos impactos iniciais da pandemia da COVID-19 na demanda dos escritórios de contabilidade, houve um aumento considerável de trabalho, sobretudo nas primeiras semanas após a chegada da pandemia no país, relacionado principalmente aos aspectos trabalhistas e tributários. Acerca deste questionamento, os respondentes utilizam termos como "trabalhando mais de 24 horas por dia" (E1), "foram semanas bem corridas" (E2), "foi bem loucura" (E2), "foi loucura mesmo" (E3), "devemos ter recebido por semana mais de mil mensagens de WhatsApp" (E4). Os entrevistados relatam, ainda, que o contador estava sendo visto como um apoio para o 
entendimento das opções decorrentes das publicações de medidas provisórias (suspensão e redução de jornada de trabalho, por exemplo), prorrogações de prazos fiscais e trabalhistas e possíveis acordos trabalhistas vinculados ao momento crítico da pandemia. Estas percepções podem ser captadas pelas falas dos entrevistados E2, E3, E5 e E6, conforme sintetizado na Tabela 4.

Tabela 4

\section{Percepção do apoio dos escritórios de contabilidade para com as empresas}

\begin{tabular}{c|l}
\hline Entrevistado 2 & $\begin{array}{l}\text { [...] porque eu senti meio que como o médico assim, na hora que eu estou morrendo eu vou lá } \\
\text { falar com o contador [...] aí sim surge uma necessidade do empresário de ter o contador do lado, } \\
\text { problemas. [...] mas foi no sentido de pedir um auxílio, uma orientação, então eu senti bastante } \\
\text { isso sim. }\end{array}$ \\
\hline Entrevistado 3 & $\begin{array}{l}{[\ldots] \text { ele não tem o que fazer com o funcionário dele, aí ele liga pra cá: 'O que que eu faço? O }} \\
\text { governo lançou alguma lei? Alguma medida provisória?' }\end{array}$ \\
\hline Entrevistado 5 5 & $\begin{array}{l}{[\ldots] \text { por mais que muitos empresários dizem que o contador é um mal necessário, mas nessa hora }} \\
\text { é o contador que resolve problema [...] os nossos funcionários passaram muito tempo nesses } \\
\text { últimos dois meses mais entendendo o que tem que ser feito do que fazendo, porque realmente } \\
\text { foi atingido essa parte }\end{array}$ \\
\hline Entrevistado 6 & $\begin{array}{l}\text { Então a nossa demanda aumentou muito nisso, como eu te falei, praticamente nesses dois meses } \\
\text { a gente se transformou em uma consultoria de departamento pessoal, algumas poucas demandas } \\
\text { que aumentaram na parte tributária [...] }\end{array}$ \\
\hline
\end{tabular}

Fonte: Dados da pesquisa (2020).

Em consonância ao que já foi relatado, os entrevistados indicaram haver a percepção de que o contador é visto pelas empresas como suporte gerencial diante de uma pandemia como a da COVID-19, mencionando que os empresários perceberam uma maior dependência do contador, aceitaram mais sugestões e demonstraram mais respeito pelo trabalho executado por esse profissional, como apresentado pelos entrevistados. O Entrevistado 1 cita que "[...] senti sim que eles perceberam a grande dependência do contador, bastante, isso eles perceberam sim [...]" (E1). Adicionalmente, os entrevistados E2, E4 e E5 apresentam percepções semelhantes, como apresentado na Tabela 5.

\section{Tabela 5}

\section{Percepção do suporte gerencial por parte dos escritórios para com as empresas}

\begin{tabular}{|c|c|}
\hline Entrevistado 2 & $\begin{array}{l}\text { Eu acho que no momento de desespero, o empresário acaba aceitando que o contador entre como } \\
\text { um suporte de fato né, e não apenas como fechamento ou manutenção da rotina contábil [...]. } \\
\text { Mas senti sim, uma diferença na procura e na aceitação dessa participação do contador em meio } \\
\text { à pandemia. }\end{array}$ \\
\hline Entrevistado 4 & $\begin{array}{l}\text { [...] a gente percebeu, eu percebi, principalmente, uma aproximação muito maior do contador } \\
\text { com o empresário no sentido de tomada de decisão, por exemplo, seja numa análise de redução, } \\
\text { suspensão de contrato de trabalho, de projeção, ou ajudar muitos empresários a reavaliar os novos } \\
\text { negócios ou novas possibilidades de negócio, redesenhar seu próprio negócio e entender como } \\
\text { financeiramente isso pode afetar, ou até mesmo ajudar no processo de decisão de obtenção de } \\
\text { financiamento [...]. }\end{array}$ \\
\hline Entrevistado 5 & $\begin{array}{l}\text { [...] mas nesse momento da crise, muitos empresários passaram a valorizar e respeitar o trabalho } \\
\text { do contador por ver o quanto o contador pode estender a mão, pode ajudar nesse momento. }\end{array}$ \\
\hline
\end{tabular}
Fonte: Dados da pesquisa (2020).

Parece haver, portanto, um direcionamento para a utilização de informações contábeis para a gestão dos desafios das empresas que são auxiliadas pelos escritórios de contabilidade, cujos proprietários foram entrevistados frente à crise do novo coronavírus, que se coaduna ao que defende Ahmad (2012) em termos do uso de tais informações, principalmente por empresas de portes menores: devem ser utilizadas para o enfrentamento de possíveis desafios durante a sua existência. Cabe salientar que, em meio a uma pandemia como a vivenciada atualmente, a parceria 
do contador em decisões relacionadas à gestão de pessoal, como redução de carga-horária, demissão, férias, entre outros, pode ser fundamental para a garantia da manutenção da organização.

Sobre a visão de como o escritório funciona como um elemento para manutenção da saúde das empresas e de como a crise do novo coronavírus, mesmo em seus estágios iniciais, mudou tal visão, constatou-se que os participantes veem dois perfis distintos de clientes. De um lado, aquele que, em geral, possui maior porte e visualiza a contabilidade como uma fonte de informações. De outro, o empresário que vê o contador apenas como um custo para o seu negócio. Neste aspecto, foram utilizados termos como "Eu acredito que nós temos os dois perfis" (E5), "clientes de vários modelos" (E4) e "depende muito do porte da empresa" (E6). Assim, tais achados parecem estar relacionados aos de Prihastiwi e Sholihin (2018) no que diz respeito, principalmente, ao tamanho e às características dos gestores, que possuem a capacidade de influenciar a percepção sobre a capacidade do escritório de contabilidade ou do contador como fontes de informações para a manutenção da saúde de suas empresas. Com relação às mudanças provocadas pela pandemia, os relatos não evidenciam unanimidade, mas apresentam, em sua maioria, visões positivas, como pode ser visualizado nas falas dos entrevistados E1, E4, E5 e E6, apresentadas na Tabela 6.

Tabela 6

\section{Mudanças provocadas pela pandemia}

\begin{tabular}{c|l}
\hline Entrevistado 1 & $\begin{array}{l}\text { Com certeza a crise gerada pela COVID pode mudar essa visão, eu vejo que a partir daí eles vão } \\
\text { ter uma visão diferente [...]. A necessidade vai fazer com que as empresas busquem muito mais } \\
\text { a contabilidade hoje do que antes da pandemia, muito provavelmente, não posso afirmar isso com } \\
\text { certeza, mas eu creio que vai ser uma mudança bastante significativa nesse ponto aí. }\end{array}$ \\
\hline Entrevistado 4 & $\begin{array}{l}\text { com certeza, vai mudar e já está mudando [...] então eu acredito que essa crise toda vai trazer } \\
\text { essa mudança muito digital na visão da contabilidade, da necessidade de informações [...]. }\end{array}$ \\
\hline Entrevistado 5 & $\begin{array}{l}{[\ldots] \text { se a pandemia pode afetar, pode, como eu disse, nós temos cliente que não viam o valor e }} \\
\text { vão passar a enxergar a partir desse momento, então eu acredito que pode sim. }\end{array}$ \\
\hline Entrevistado 6 & $\begin{array}{l}\text { Sobre a COVID-19, sim, algumas empresas, a percepção acaba mudando, para eles poderem ver } \\
\text { a contabilidade de uma maneira um pouco diferente [...]. }\end{array}$ \\
\hline
\end{tabular}

Fonte: Dados da pesquisa (2020).

Em relação aos serviços de suporte gerencial ofertados aos clientes e às mudanças decorrentes da pandemia da COVID-19, notou-se que há uma categorização das respostas, que se dividem entre escritórios de contabilidade que não ofertavam o serviço, outros que ofertavam como um adicional e aqueles que ofertavam juntamente com os demais serviços fornecidos. $\mathrm{O}$ escritório que não ofertava continuou não oferecendo suporte gerencial aos seus clientes. Entre os que ofertavam como um serviço adicional, observou-se que em um dos casos não houve mudanças, enquanto no outro houve uma mudança no fornecimento do serviço em função de uma maior procura por parte dos clientes, principalmente relacionado ao aspecto financeiro e departamento pessoal, como evidenciado na fala do entrevistado E1.

Meu escritório é um pouco diferenciado, ele não fica só na operação, ele também fica bastante na gestão, mas é uma particularidade minha porque eu agrego junto uma questão de consultoria mais técnica de gestão [...]. O que aconteceu depois da pandemia, [...] foi participar um pouco das decisões [...] com relação à questão mais financeira um pouco [...], a gente participou mais disso, então, suspensão de contrato de trabalho, como isso vai impactar no custo, suspensão, por exemplo, de impostos, então, deu uma modificada nesse ponto (E1)

Quanto aos escritórios de contabilidade que ofertavam o suporte gerencial juntamente com os demais serviços, percebeu-se mudanças relacionadas principalmente às demandas dos clientes, mas não necessariamente à inclusão de novas ferramentas ou técnicas gerenciais, como pode ser identificado a partir das falas dos entrevistados E4, E5 e E6. O E4 ponderou que "eles alteraram 
pouco, acho que aumentaram, veem aumentando, cliente pedindo ajuda [...] então tem surgido bastante trabalho neste aspecto também, que não teria acontecido talvez se não tivesse a COVID19 " e "eu tenho, por incrível que pareça, tem algumas empresas que tem me ligado, estou fazendo consultoria para empresas que não são meus clientes de contabilidade [...]" (E4). Além disso, o E5 mencionou que "[...] se alteraram assim, no sentido de aumento, no sentido de que a cada momento surge novas dúvidas, você tem que dar esse suporte, nesse sentido sim [...]" (E5). Finalmente o E6 afirmou que

[...] o que mudou agora [...], que foi quando começou a entrar decreto atrás de decreto e fechamento de empresas, então mudou bastante o foco do nosso cliente aqui do escritório, que o nosso cliente se voltou bastante para a parte de departamento pessoal [...] (E6)

Deve-se salientar que o suporte gerencial, quando ofertado pelos escritórios de contabilidade, consiste em ferramentas relacionadas principalmente ao primeiro estágio da contabilidade gerencial apresentado pelo IFAC (1998), com decisões voltadas sobretudo aos aspectos financeiros. No entanto, para que esse cenário possa ser modificado, é necessário envolvimento de ambas as partes (contadores e empresários), com uma busca conjunta que leve ao uso de informações e ferramentas gerenciais de estágios mais avançados. Nesse ponto, a pandemia da COVID-19 parece ter sido, ainda que de forma lenta e gradual, um impulso para que tal situação seja modificada.

Em termos da modificação da visão acerca das possibilidades de oferta de suporte gerencial pelos escritórios de contabilidade para as empresas em função da COVID-19, as falas dos entrevistados caminham para uma sinalização de que a mudança já vinha acontecendo na perspectiva do contador, mas com restrição por parte dos clientes, como evidenciado anteriormente. Nesse sentido, parece que a crise gerada pela COVID-19, ainda em fase inicial, acelerou o processo de convergência acerca da visão de utilidade do suporte gerencial entre o contador e o cliente, gerando uma tendência para o entendimento de que a contabilidade, por meio de tal ferramenta, pode estar presente como geradora de informações no processo de tomada de decisão, auxiliando o empresário. Este entendimento pode ser observado nas falas dos entrevistados E1, E2, E3 e E4. O E1 defendeu que "a crise vai trazer um profissional mais de conhecimento, mais técnico pra auxiliar no suporte e vai afastar um pouco mais o suporte mecânico, o suporte operacional" (E1). Além disso, os E2, E3 e E4 apresentam a mesma visão, conforme sintetizado na Tabela 7.

\section{Tabela 7}

\section{Percepção da utilidade do suporte gerencial}

\begin{tabular}{c|l}
\hline Entrevistado 2 & $\begin{array}{l}\text { Eu acho que até em questão de contador, talvez assim, tenha dado um feeling um pouco maior, } \\
\text { mas eu acho que o contador traz há muito tempo [...], mas agora talvez tenha mais possibilidade } \\
\text { e mais abertura de se tornar concreto, digamos. }\end{array}$ \\
\hline Entrevistado 3 & $\begin{array}{l}{[\ldots] \text { então eu acho que a COVID-19 só acelerou um processo que já vinha sendo desenvolvido }} \\
{[\ldots] .}\end{array}$ \\
\hline Entrevistado 4 & $\begin{array}{l}\text { Não, eu acho que a COVID-19 não modificou, eu acho que ela intensificou no caso, como falei, } \\
\text { isso já vinha acontecendo na nossa área [...] não foi a COVID-19 que está modificando a } \\
\text { necessidade de gerar informações gerenciais para os clientes, acho que isso já vinha acontecendo, } \\
\text { já vinha num cenário, tanto é que se fala que a contabilidade como a gente conhece, dois três anos } \\
\text { atrás se falava que ia acabar e é uma realidade [...]. }\end{array}$ \\
\hline
\end{tabular}

Fonte: Dados da pesquisa (2020).

No que diz respeito ao relacionamento entre cliente e escritório de contabilidade, parece haver uma noção de estreitamento da relação, seja gerada diretamente pela COVID-19 ou acelerada por ela. Além disso, identificou-se uma percepção de distanciamento da característica operacional da contabilidade, normalmente ofertada pelos escritórios de contabilidade, e o 
direcionamento da oferta de uma contabilidade com características mais gerenciais, tanto no curto quanto no longo prazo. Estes achados podem ser confirmados pelas falas dos entrevistados E1, E2, E3, E4 e E6, conforme apresentado na Tabela 8.

\section{Tabela 8}

\section{Percepção do estreitamento da relação entre clientes e contadores}

\begin{tabular}{|c|c|}
\hline Entrevistado 1 & $\begin{array}{l}\text { Então, essa crise vai aproximar um pouquinho mais as empresas do contador que parte para essa } \\
\text { linha de gestão, talvez, uma suposição, e vai afastar, distanciar um pouco mais, aquele que não } \\
\text { opera nessa linha, que apenas faz uma reprodução mecânica dos dados, eu acho que isso a crise } \\
\text { vai selecionar um pouquinho, essa relação vai ficar mais estreita, do ponto de vista da parceria, } \\
\text { da confiança, do conhecimento e menos da parte operacional, uma opinião. }\end{array}$ \\
\hline Entrevistado 2 & $\begin{array}{l}\text { [...] eu acho que o cliente ele vai entendendo mais o que que o universo da contabilidade pode } \\
\text { trazer pra ele, não só em questão de segurança legal, contábil e tudo mais, mas também em questão } \\
\text { planejamento financeiro e outras ferramentas que a gente acaba não entrando tão a fundo por esse } \\
\text { bloqueio entre partes né. [...] Acho que pode ter uma mentalidade diferente, acho que não vai ser } \\
\text { nada muito radical, eu vejo que ainda existe muito esse bloqueio, essa mentalidade fechada, mas } \\
\text { eu acho que pode sim trazer alterações. }\end{array}$ \\
\hline Entrevistado 3 & Eu acho que vai mudar bastante, no curto prazo. \\
\hline Entrevistado 4 & $\begin{array}{l}\text { Eu acho que essa mudança já vem ocorrendo, não é a COVID-19 que vai fazer essa mudança } \\
\text { acontecer [...] Então a COVID-19, talvez acelere um pouco esse processo [...] então isso já vinha } \\
\text { acontecendo, com a COVID-19 eu acho que isso intensifica porque agora ele precisa tomar } \\
\text { decisões rápidas [...]. }\end{array}$ \\
\hline Entrevistado 6 & $\begin{array}{l}\text { [...] agora aquela empresa que viu nisso uma oportunidade, ou então viu a hora de mudar a forma } \\
\text { de atuação dela nisso, acaba que vai estreitar mais os laços, porque como você está mudando de } \\
\text { ramo talvez, ou de forma de atuação, ou você viu a real utilização da contabilidade ou das } \\
\text { informações que a gente gera, esse cara ele vai estreitar bastante os laços, no sentido de aumentar } \\
\text { uma demanda mais voltada para consultoria, para o gerenciamento das empresas [...]. }\end{array}$ \\
\hline
\end{tabular}

Fonte: Dados da pesquisa (2020).

O entendimento acerca do estreitamento da relação entre contadores - ou escritórios de contabilidade - e seus clientes pareceu amenizar um dos problemas evidenciados a partir dos achados de Santos et al. (2018) em termos dos ruídos aparentemente existentes na comunicação entre eles, gerando um ambiente de maior integração onde a oferta de suporte gerencial pode ser ampliada, permitindo a oferta de ferramentas que auxiliem as empresas na gestão dos negócios.

Percebe-se, portanto, que os impactos iniciais gerados pela COVID-19 na oferta de suporte gerencial pelos escritórios de contabilidade ocorreram, principalmente, como consequência do aumento das demandas dos clientes que necessitavam de decisões rápidas e do entendimento das possibilidades e reflexos financeiros e operacionais das tomadas de decisão. Ressalta-se, ainda, que essa demanda ocorreu sobretudo devido às medidas provisórias e alterações de legislação adotadas na chegada do vírus no Brasil. Além disso, tem-se visto, na crise, uma oportunidade de aproximação entre clientes e escritórios de contabilidade, contribuindo ou acelerando o movimento de valorização do contador e do serviço prestado pelos escritórios de contabilidade no que concerne o aspecto gerencial. Essas visões parecem estar mais presentes entre empresas de maior porte atendidas pelos escritórios de contabilidade, enquanto as micro e pequenas empresas parecem estar, ainda, em estágio inicial quanto à tal aproximação.

\section{CONSIDERAÇÕES FINAIS}

Este estudo teve como objetivo identificar como a crise causada pela COVID-19 afetou o suporte gerencial ofertado pelo contador a partir da análise de entrevistas com 6 escritórios de contabilidade localizados nos Estados de São Paulo, Paraná e Santa Catarina. A partir dos dados, identificou-se que a crise da COVID-19, ainda em estágio inicial no Brasil, apresentou potencial para mudanças na relação entre escritórios de contabilidade e seus clientes, impactando no suporte ofertado pelos contadores. 
Dessa forma, percebe-se que as consequências decorrentes da crise causada pela COVID19, vivenciada pelas empresas, ocasionaram um processo de ampliação do entendimento sobre o papel da contabilidade, por meio dos escritórios e seus contadores, no que tange ao processo de tomada de decisão, influenciado para um aumento do suporte gerencial oferecido pelas empresas de serviços contábeis. Neste aspecto, parece, ainda, que tanto o porte e estrutura dos escritórios de contabilidade como das empresas tomadoras dos serviços impacta a oferta e a adoção de noções e ferramentas relacionadas ao suporte gerencial.

Assim, buscou-se contribuir para o entendimento das formas como a COVID-19, ainda que em estágio inicial, tem influenciado as relações humanas e, principalmente, as profissionais no âmbito da contabilidade. Nesse sentido, o conhecimento gerado a partir dos resultados deste estudo pode contribuir para o enfrentamento e entendimento de outras crises/contingências que possam ocorrer, como desastres ambientais, greves, paralisação de serviços públicos essenciais, entre outros. Além disso, também contribui ao mostrar as oportunidades, decorrentes do momento vivenciado, para que os escritórios de contabilidade se aproximem de seus clientes, possibilitando a sua inserção no processo decisório das empresas, o auxílio na superação da crise atual e maior geração de valor a partir do serviço ofertado.

Como implicações há, portanto, um momento para que escritórios de contabilidade - em posse de sua capacidade de auxiliar as empresas na superação da crise - tomem para si uma oportunidade de amenizar o sofrimento dos empresários, auxiliando-os em tomadas de decisões que permitam a sobrevivência de seus negócios durante as contingências enfrentadas no período e, ao mesmo tempo, de apresentarem-se como fonte de informações e de suporte, principalmente gerencial, que pode gerar valor para as empresas mesmo em momentos não tão delicados como o atual. Nesse sentido, surge uma oportunidade para que contadores ampliem para os empresários o entendimento de que a contabilidade pode ir além do aspecto operacional, com o fornecimento de ferramentas ou técnicas gerenciais, simples ou complexas, que podem auxiliar a gestão das empresas.

Os resultados devem ser interpretados considerando algumas limitações, como o uso de entrevistas e o momento em que o estudo foi realizado - quando os efeitos da COVID-19 podem não ter sido sentidos completamente, visto que as entrevistas foram feitas ainda em momento inicial de enfrentamento da pandemia. Além disso, deve-se considerar que o porte dos clientes que os participantes da pesquisa atendem foi obtido a partir da percepção dos entrevistados, levando em conta, principalmente, aspectos tributários. Outras limitações dizem respeito ao perfil dos entrevistados, que durante suas falas utilizaram expressões verbais diretas e simples, e à realidade do tipo de empresa utilizado na pesquisa (escritórios de contabilidade). Ademais, sugere-se a realização de pesquisas que busquem a ampliação do escopo de participantes em termos quantitativos ou qualitativos, que analisem as relações investigadas neste estudo com uma ampliação do período em relação ao surgimento da pandemia da COVID-19, buscando identificar os efeitos gerados a longo prazo, e pesquisas que ampliem os achados deste estudo analisando, por exemplo, a divergência entre teoria e prática quanto aos aspectos relacionados ao suporte gerencial e como a pandemia alterou (ou não) essas diferenças.

\section{REFERÊNCIAS}

Abdel-Kader, M. G., \& Luther, R. G. (2006). IFAC's conception of the evolution of management accounting. Advances in Management Accounting, 15, 229-247.

Ahmad, K. (2012). The use of management accounting practices in Malaysian SMEs. Dissertation $(\mathrm{PhD})$, University of Exeter, United Kingdom. 
Ahmad, K., \& Zabri, S. M. (2016). Management accounting practices among small and medium enterprises. Proceedings of the 28th International Business Information Management Association Conference, 9, 10.

Armitage, H. M., Webb, A., \& Glynn, J. (2016). The use of management accounting techniques by small and medium-sized enterprises: a field study of Canadian and Australian practice. Accounting Perspectives, 15(1), 31-69.

Bardin, L. (2009). Análise de conteúdo. Lisboa: Edições 70.

Bauer, M. W. (2015). Análise de conteúdo clássica: uma revisão. In M. R. Bauer, \& Gaskell, G. (Orgs). Pesquisa qualitativa com texto, imagem e som: um manual prático. Petrópolis, RJ: Vozes.

Brasil. (2020) Painel de casos de doença pelo coronavírus 2019 (COVID-19) no Brasil pelo Ministério da Saúde. Recuperado de https://covid.saude.gov.br

Cao, W., Fang, Z., Hou, G., Han, M., Xu, X., Dong, J., \& Zheng, J. (2020). The psychological impact of the COVID-19 epidemic on college students in China. Psychiatry research, 112934.

Chahrour, M., Assi, S., Bejjani, M., Nasrallah, A. A., Salhab, H., Fares, M., \& Khachfe, H. H. (2020). A bibliometric analysis of Covid-19 research activity: A call for increased output. Cureus, 12(3).

Chenhall, R. H., \& Langfield-Smith, K. (1998). Adoption and benefits of management accounting practices: an Australian study. Management accounting research, 9(1), 1-19.

Crawford, J., Butler-Henderson, K., Rudolph, J., Malkawi, B., Glowatz, M., Burton, R., Magni, P., \& Lam, S. (2020). COVID-19: 20 countries' higher education intra-period digital pedagogy responses. Journal of Applied Learning \& Teaching, 3(1), 1-20.

Ferreira Junior, R. R. F., \& Santa Rita, L. P. (2020). Impactos da Covid-19 na Economia: limites, desafios e políticas. Cadernos de Prospecção, 13(2), 459-476.

Flick, U. (2008). Introdução à pesquisa qualitativa. Porto Alegre: Artmed.

Gaskell, G. (2015). Entrevistas individuais e grupais. In M. R. Bauer; G. Gaskell (Orgs). Pesquisa qualitativa com texto, imagem e som: um manual prático. Petrópolis, RJ: Vozes.

Green, F. B., \& Amenkhienan, F. E. (1992). Accounting innovations: a cross sectional survey of manufacturing firms. Journal of Cost Management for the Manufacturing Industry, 6(1), 5864.

$\begin{array}{cccccc}\text { International } & \text { Federation of } & \text { Accountants } & \text { (IFAC) } & \text { (1998). } & \text { International } \\ \text { Management } & \text { Accounting } & \text { Practice } & \text { Statement: } & \text { Management }\end{array}$ Accounting Concepts. New York.

Institute of Management Accountants (IMA). (2008). Definition of Management Accounting. Statements on Management Accounting. 
Kraemer, M. U., Yang, C. H., Gutierrez, B., Wu, C. H., Klein, B., Pigott, D. M., ..., \& Brownstein, J. S. (2020). The effect of human mobility and control measures on the COVID-19 epidemic in China. Science, 368(6490), 493-497.

Lukka, K., \& Granlund, M. (2002). The fragmented communication structure within accounting academia: the case of activity-based costing research genres. Accounting, Organizations and Society, 27(1), 165-190.

Martins, G. A., \& Theóphilo, C. R. (2016). Metodologia da investigação científica para ciências sociais aplicadas. São Paulo: Atlas.

Massan, S., Shaikh, M. M., \& Dahri, A. S. (2020). Effect of COVID-19 epidemic on research activity of researcher in Pakistan Engineering University and its solution via technology. $3 C$ Tecnología. Glosas de innovación aplicadas a la pyme, (Edición Especial), 249-263.

Minayo, M. C. S. (2017). Amostragem e saturação em pesquisa qualitativa: consensos e controvérsias. Revista pesquisa qualitativa, 5(7), 1-12.

Organização Mundial da Saúde (OMS). (2020). Coronavirus disease 2019 (COVID-19) - Situation Report - 51. Recuperado de https://www.who.int/docs/default-source/coronaviruse/situationreports/20200311-sitrep-51-covid-19.pdf?sfvrsn=1ba62e57_10

Organização Mundial da Saúde (OMS). (2021). WHO Coronavirus (COVID-19) Dashboard - 01 June 2021. Recuperado de https://covid19.who.int/

Polizzi, C., Lynn, S. J., \& Perry, A. (2020). Stress and Coping in the Time of Covid-19: Pathways to Resilience and Recovery. Clinical Neuropsychiatry, 17(2).

Prihastiwi, D. A., \& Sholihin, M. (2018). Factors Affecting the Use of Management Accounting Practices in Small and Medium Enterprises: Evidence from Indonesia. Journal Dinamika Akuntansi, 10(2), 158-176.

Sahu, P. (2020). Closure of universities due to Coronavirus Disease 2019 (COVID-19): impact on education and mental health of students and academic staff. Cureus, 12(4).

Sampieri, R. H., Collado, C. F., \& Lucio, P. B. (2013). Metodologia da Pesquisa. São Paulo: McGrauw-Hill, 2013.

Santos, V. D., Bennert, P., Figueiredo, G. H., \& Beuren, I. M. (2018). Uso dos instrumentos de Contabilidade Gerencial em pequenas e médias empresas e seu fornecimento pelo escritório de Contabilidade. Pensar Contábil, 20(71).

Sargiacomo, M., Ianni, L., \& Everett, J. (2014). Accounting for suffering: Calculative practices in the field of disaster relief. Critical Perspectives on Accounting, 25(7), 652-669.

Sintema, E. J. (2020). Effect of COVID-19 on the performance of grade 12 students: Implications for STEM education. Eurasia Journal of Mathematics, Science and Technology Education, 16(7), 1851. 
Wang, C., Pan, R., Wan, X., Tan, Y., Xu, L., Ho, C. S., \& Ho, R. C. (2020). Immediate psychological responses and associated factors during the initial stage of the 2019 coronavirus disease (COVID-19) epidemic among the general population in China. International journal of environmental research and public health, 17(5), 1729. 